\title{
Measuring Health-related Quality of Life in Cuban Patients with Head and Neck Cancer
}

\author{
Josefina Lugo-Alonso MD, José R. Díaz-Martínez MD, Nélido González-Fernández MD, Mario Luzardo-Verde PhD, \\ Leticia Fernández-Garrote DDM PhD, Gladys E. López-Bujáns DDM, Argelia Collazo-de la Maza MD
}

\begin{abstract}
INTRODUCTION Quality of life measurement is an important aspect of comprehensive clinical assessment. It does not have a set definition, but changes according to sociocultural context. Head and neck cancer patients experience substantially decreased healthrelated quality of life. The Cuban public health system needs to develop its own instrument to measure these patients' quality of life.
\end{abstract}

OBJECTIVES. Construct and validate an instrument to measure quality of life in Cuban patients with nasopharyngeal, laryngeal, oral or mesopharyngeal cancer.

METHOD The sample comprised adult patients treated for nasopharyngeal, laryngeal, oral or mesopharyngeal cancer in Cuba's National Oncology and Radiobiology Institute in 2013 and 2014. To construct and validate the instrument, we selected a sample of 520 patients. Initial interviews were held until no substantially new information emerged; 40 patients were selected to participate in focus groups to identify important problems leading to decreased health-related quality of life. Face validity of the preliminary questionnaire was assessed with 40 patients. Internal consistency and validity were assessed with 400 patients. Score stability was assessed with another 40 patients using a test-retest design. There were 24 experts who participated in the process, 15 in the construction phase and 9 in the content validity evaluation of the preliminary version. Assessment of reliability and validity was based

\section{INTRODUCTION}

Health-related quality of life (HRQOL) does not have a set definition, but changes according to sociocultural context. It is a multidimensional construct that includes physical functioning, psychosocial functioning and family relationships, disease symptoms and treatment side effects. HRQOL is influenced by personal, social, family and financial factors. Perceived HRQOL changes according to a person's experiences, life goals and plans. Disease symptoms and treatment side effects decrease cancer patients' personal satisfaction and sources of gratification; adapting to life with cancer or maintaining an acceptable level of $\mathrm{HRQOL}$ is also associated with reducing negative emotions.[1-3]

The following statistics support our interest in studying HRQOL in patients with head and neck cancers. Laryngeal cancer incidence in Cuban men increased from 846 to 1139 diagnosed cases between 2007 and 2012 (age-adjusted rates of 11.2 and 14.0 per 100,000 population, respectively). In 2010 and 2012, lip, mouth and pharyngeal cancer had the fourth highest incidence rate among all cancers for both sexes (age-adjusted rates of 12.9 and 14.2 per 100,000 , respectively), with 1020 and 1167 new cases, respectively.[4-7] Treatment options for these tumors continue to be surgery, radiotherapy and chemotherapy. Chemotherapy and radiotherapy are the standard treatments for clinical stages III and IV. Despite their efficacy in locoregional tumor control, high morbidity from their side effects negatively impacts patients' on internationally recognized approaches, including Cronbach alpha and empirical verification of convergent, discriminant, clinical and predictive validity. Response burden was also assessed (completion time and item nonresponse).

RESULTS A 65-item questionnaire, CV-IOR-CyC-01, was developed and validated, with three domains (physical functioning, psychosocial functioning and family relationships, disease symptoms and treatment side effects) and two ungrouped questions on perceived general health and perceived health-related quality of life. The instrument displayed satisfactory reliability (homogeneity and stability) and validity (face, content, convergent, discriminant, clinical and predictive). Test-retest correlation was strong. Large differences and a downward trend in health-related quality of life across clinical stages and moderate or high standardized response mean values reflect good clinical and predictive validity. Response burden was acceptable (completion time 6.2 minutes, item nonresponse rate $1.3 \%-3.8 \%$ ).

CONCLUSIONS CV-IOR-CyC-01's psychometric properties justify its use in clinical trial protocols with patients with nasopharyngeal, laryngeal, oral or mesopharyngeal cancer.

KEYWORDS Validation studies, psychometrics, health-related quality of life, head and neck cancer, head and neck neoplasms, qualitative research, Cuba

HRQOL. Physical effects of cancer and its treatment can especially diminish HRQOL related to communication, swallowing, chewing, nutrition and body image, and should be included in an instrument to assess HRQOL in these patients.[8-10]

Measuring and monitoring $\mathrm{HRQOL}$ are part of comprehensive assessment of short- and long-term therapeutic benefits in clinical oncology, and are criteria for excellence in medical care. HRQOL measurement is important for planning and evaluating the impact of new health technologies at different levels of care, evaluating health programs and services, and developing cancer care policies. Attention to HRQOL improves doctor-patient communication and is an important consideration for patientcentered planning and community-support models.[11,12]

An instrument is valid if it fulfills the purposes for which it was created. Validity is assessed both empirically and theoretically. Face validity and content validity are assessed on theoretical grounds. Empirical validation is criterion based.[13] Some important criteria commonly used include convergent validity (high correlation with other measures of the same construct), divergent or discriminant validity (low correlation with other measures of a different construct), clinical validity (ability to detect differences between groups known to be different) and predictive validity (sensitivity to change). Another important aspect of such instruments is their internal consistency, or reliability.[13] 
Various instruments are utilized to measure HRQOL, but none is universally accepted.[14,15] The most recognized and used internationally have been developed for English-speaking populations; some have been translated into Spanish and adapted, but there are no HRQOL questionnaires adapted to Cuba's sociocultural characteristics.

Development of a Cuban instrument is needed to provide a culturally appropriate tool and allow for comparisons within the country.

The objective of this study was to develop and validate a first HRQOL instrument for head and neck cancer patients (nasopharyngeal, laryngeal, oral and mesopharyngeal), offering it as a tool that, in its final version, could be extended by medical personnel throughout Cuba's universal public health system.

\section{METHODS}

Study type and population This instrument development study was carried out at Cuba's National Oncology and Radiobiology Institute (INOR) in 2013 and 2014. All patients were selected from INOR outpatient clinics using a nonprobabilistic sample. Inclusion criteria were: age >18 years; histological diagnosis of nasopharyngeal, laryngeal, oral or mesopharyngeal cancer; suitability for cancer treatment, which includes surgery, chemotherapy, and radiotherapy alone or a combination of two or more of these procedures. Patients unable to communicate orally or in writing; with mental disability; or with signs of psychopathology, senile dementia or brain metastases were excluded. Development and instrument validation phases overlapped.

Construction stage Instrument items were developed based on information supplied by patients who attended their last cancer treatment session and agreed to be interviewed and speak about their problems in focus groups. Sample size was determined using the information saturation criterion.[16] Interviews stopped when there were no new points and the last five patients reported points that had already been mentioned. A question guide was created to keep interviews uniform (Table 1), covering aspects of $\mathrm{HRQOL}$ documented in a literature review. All interviews were held in a private setting. To encourage spontaneity, no recording equipment was used; notes were taken on responses. Participants were asked to stay on topic for each question asked. A total of 40 patients participated in the focus groups, 20 men and 20 women, in 8 groups of 5 patients each.

Information provided by both interviews and focus groups was interpreted qualitatively by 15 experts who issued a technical report. Using this input, the authors created a list of 77 problems, organized by domain, of which 13 related to general physical functioning and the aerodigestive tract, 30 to psychosocial functioning and family relationships, and 34 to symptoms and treatment side effects. These problems were then submitted for review by a nominal group of 15 experts with at least 15 years of experience in treating patients with head and neck cancers (5 head and neck oncologists, 5 radiotherapists, 2 psychologists and 3 nurses). The nominal group suggested eliminating three problems referring to symptoms and treatment side effects that are infrequent in this group of patients: inability to eat orally, burning eyes and pain at injection site.

\section{Table 1: Focus group question guide}

The following questionnaire is intended to identify aspects related to quality of life that you consider important. Please answer each question as clearly as possible

1. Financial:

If your disease has caused you financial difficulties, please explain why.

Do these financial difficulties cause you any stress?

2. Physical dysfunction:

- What are your physical limits for self-care and activities at home and outside the home?

What physical activities that you used to carry out before getting sick or before treatment now present a certain degree of limitation for you?

3. Disease symptoms and side effects of cancer treatment: List all the unwanted symptoms you feel since your treatment that are important to your quality of life.

4. Psychosocial dysfunction: Does the treatment affect your emotional state? Explain. Is your personality the same as before you became sick? What is the same and what has changed? What negative emotional consequences have you experienced? What, if anything, prevents you from carrying on your usual social life?

Has your relationship with your family changed? If so, in what way?

- Do you feel that the disease or treatment has affected your relationship with your partner?

- What physical limitations have been caused by the treatment?

- Has your self-esteem or body image been affected by this disease?

How do you feel that those closest to you have reacted to your disease and chemotherapy and radiotherapy treatments?

A preliminary version of the questionnaire, CV-IOR-CyC-VP, was constructed with the 74 remaining problems, distributed among the domains of physical functioning, psychosocial functioning and family relationships, disease symptoms and treatment side effects (31 items) and two ungrouped items: perceived general health and perceived HRQOL. Items were written clearly and plainly, avoiding technical jargon. Likert-like scales were designed with five response options;[17] values ranged from 1 to 5 , with higher values indicating better HRQOL.

Synthetic variables were created to summarize participant responses by calculating mean scores for each domain and the global HRQOL scale as follows:

- physical functioning (PhF)

- psychosocial functioning and family relationships (PsF)

- disease symptoms and treatment side effects (Sx)

- perceived health $(\mathrm{PH})$

- $\mathrm{HRQOL}=(\mathrm{PhF}+\mathrm{PsF}+\mathrm{Sx}+\mathrm{PH}) / 4$

Face validity was assessed by 40 patients who met selection criteria. They were asked to respond to CV-IOR-CyC-VP; to comment on its clarity, simplicity and length; and to add any problems affecting their HRQOL not included. 
An expert group comprising 7 head and neck oncologists and 2 psychologists, all with $>15$ years of experience, assessed CV-IORCyC-VP's content validity. Each item was evaluated according to whether it:

- was important to patients;

- was easy for patients to understand;

- was clearly and explicitly associated with the concept of HRQOL being measured;

- contained wording consistent with response choices;

- could elicit varying responses among different patients;

- contained items whose wording was compatible with their operationalization (scale categories were equidistant and hierarchically related to the data); and

- did not violate ethical principles.

Changes derived from these evaluations were incorporated into Version 1 of the instrument, CV-IOR-CyC-01.

Validation phase CV-IOR-CyC-01 was administered to 400 patients who met selection criteria at three different points: before cancer treatment, immediately on completion, and four weeks following treatment completion. Reliability (homogeneity or internal consistency), convergent and discriminant validity, clinical validity, predictive validity, interpretability and response burden were assessed. With another sample of 40 patients (who met inclusion criteria and were clinically stable), CV-IOR-CyC01 's score stability was assessed with test-retest reliability at two points 30 days apart. A database was created with SPSS 19.

Cronbach alpha was calculated to test homogeneity or internal consistency, with a threshold of 0.7 . Test-retest validity was deemed satisfactory for Pearson correlation coefficients $>0.9$.

Convergent and divergent or discriminant validity were analyzed using the multitrait multimethod correlation matrix. Convergent validity is present if correlations are $\geq 0.4$ among items in the same domain, and between them and the synthetic variable of the domain to which they theoretically belong. Discriminant validity is present if correlations among items in different domains and between them and the synthetic variables of the domains to which they theoretically do not belong are $<0.4$.[18]

Despite some limitations for detecting dose-response effects, one-way ANOVA was used to assess clinical validity (ability to identify known clinical groups) for each of the three HRQOL domains, stratified by clinical stage of disease. A threshold of $p$ $\leq 0.05$ was considered for statistical significance. The Bonferroni correction was used. This analysis is based on the premise that patients in clinical stages III and IV have lower HRQOL than those in clinical stages I and II.

Predictive validity assesses an instrument's capacity to detect changes in HRQOL over time due to an event or intervention. This validity criterion is based on estimation of the amount of change in HRQOL and its domains, from calculating the standardized response mean (SRM), which is defined as

$S R M=\frac{\frac{\left(\bar{X}_{j}-\bar{X}_{i}\right)}{\bar{X}_{i}}}{S E\left(\bar{X}_{j}-\bar{X}_{i}\right)}$
... where

$\bar{X}_{i}:$ measurement in time i $(i=1,2,3)$

$\bar{X}_{j}$ : measurement in time $\mathrm{j}(\mathrm{j}=2,3)(\mathrm{i}<\mathrm{j})$

$S E\left(\bar{X}_{j}-\bar{X}_{i}\right):$ standard error of the difference between two measurements

With the three measurements taken, mean change in HRQOL was calculated at completion of chemotherapy compared to start of chemotherapy, and mean change one month after completion compared to at completion of chemotherapy. Cutoffs for Cohen's SRM for qualitative assessment of effect size are: small, <0.2; moderate, $\geq 0.2$ but $<0.8$; and large, $\geq 0.8$.[19] Clinical interpretability of the numeric value of the HRQOL score refers to ability to assign a qualitative clinical meaning to response choices, with deterioration in HRQOL expressed on a scale from 1 to 5 : severe, $\leq 2$; moderate, $>2$ but $\leq 3$; mild, $>3$ but $<5$; normal $=5$.[20]

Response burden was estimated using two indicators: mean completion time (in minutes) and item nonresponse rate. Response burden is considered excessive if response time is $>15$ minutes or nonresponse rate is $\geq 10 \%$.

Analysis Means (with SDs) and percentages were used to summarize patient responses and describe their demographic and clinical characteristics. Cronbach alpha and Pearson correlation were used to assess reliability. Convergent and discriminant validity were assessed using Pearson correlations. Clinical validity was tested with one-way ANOVA for each of the three domains. Predictive validity was assessed using SRM.

Ethics The study was approved by the INOR Research Ethics Committee. Participants provided written informed consent after study objectives and content were explained to them.

\section{RESULTS}

Of a total of 520 participants aged 26-90 years (median 61); $400(77 \%)$ were men. Some $71 \%$ reported having completed at least high school education. There were 270 patients with oral and mesopharyngeal cancer (51.9\%); 228 with laryngeal tumors $(43.8 \%)$; and 22 with nasopharyngeal $(4.2 \%)$. There was a slight preponderance of early-stage cancers: stage I, 33.1\%; stage II, 24\%; stage III, 25\%; and stage IV, 18.1\% (rounding error explains failure to sum to $100 \%$ ).

Face and content validity Face validity was satisfactory: All patients said that instrument items were simple and comprehensible; 6 of the 40 patients who participated in focus groups (15\%) said the instrument was very long. During content validity assessment, eight of nine experts suggested excluding items fear of going back to work and that your family wants to control your life from the psychosocial functioning and family relationships domain, as these problems are infrequent and the response to these items had low variation. Five experts suggested eliminating item pain intensity, because a nonspecific pain could have causes other than the cancer. The number of items was reduced on the advice of 8 experts, who contended that 14 items in the symptoms and side effects domain could be distilled into the following 6: 1) deafness, tinnitus or blocked ear; 2) mouth 
irritation, burning or sores; 3) mouth pain or dysphagia; 4) dry mouth, reduced salivation or thick saliva; 5) drooling or excessive salivation, and 6) loss of sense of taste and/or smell.

CV-IOR-CyC-01, incorporating the changes proposed, contained 65 items (9 fewer than the preliminary version), distributed among: physical functioning (13 items), psychosocial functioning and family relationships (27 items), symptoms and side effects (23 items) and 2 ungrouped items relating to perceived general health and perceived HRQOL.

Internal consistency Overall internal consistency of CV-IORCyC-01 and its domains was satisfactory as per Cronbach alpha coefficient. The psychosocial functioning and family relationships domain was the most homogeneous $(0.90)$, while the symptoms and side effects domain was the least, with a coefficient of 0.79 .

Convergent and discriminant validity The Pearson correlation matrix diagonal showed values close to unity in physical functioning (0.99) and psychosocial functioning and family relationships (0.98); this was not the case for the symptoms and side effects domain. Table 2 presents the multitrait multimethod matrix, which shows correlations between CV-IOR-CyC-01's synthetic variables at two points: the first measurement above the main diagonal and second measurement below it. There was strong Pearson correlation $(r>0.4)$ between HRQOL score and its own domains (range: $0.52-0.83$ ) both in the first and second measurement, and weak correlation $(r<0.4)$ between physical functioning and psychosocial functioning and family relationship domains in both first and second measurements ( 0.39 and 0.36 , respectively).

Clinical validity Table 3 shows mean HRQOL scores by clinical stage and statistical significance associated with one-way ANOVA. Not only were differences detected across clinical stages, but there was a consistent downward trend in scores with increasing stage, consistent with expectations based on clinical staging.

Predictive validity Table 4 displays predictive validity as measured by SRM. All domains showed decreased scores over time (with moderate and large effect sizes). A large effect size ( $\geq 0.8)$ was observed at both times in psychosocial functioning and family relationships, symptoms and side effects, $\mathrm{HRQOL}$ index and the general item perceived HRQOL. Perceived general health changed substantially between completion of treatment and one month after completion (0.83).

Table 2: CV-IOR-CyC-01 convergent and discriminant validity (multitrait multimethod matrix and test-retest ${ }^{a}$

\begin{tabular}{ll|l|l|l|l|}
\multirow{2}{*}{ Domain } & & \multicolumn{4}{|c|}{ First measurement } \\
\cline { 3 - 7 } & & PhF & Sx & PsF & $\begin{array}{c}\text { HRQOL } \\
\text { index }\end{array}$ \\
\hline \multirow{2}{*}{$\begin{array}{l}\text { Second } \\
\text { measurement }\end{array}$} & $\begin{array}{l}\text { Symptoms and side effects } \\
\text { (Sx) }\end{array}$ & 0.51 & 0.22 & 0.41 & 0.65 \\
\hline $\begin{array}{l}\text { Psychosocial functioning and } \\
\text { family relationships (PSF) }\end{array}$ & 0.39 & 0.71 & 0.90 & 0.66 \\
\hline HRQOL index & 0.54 & 0.83 & 0.52 & 0.98 \\
\hline
\end{tabular}

${ }^{a}$ correlations between synthetic variables and HRQOL index in measurements before and after treatment; test-retest results on main diagonal

babove main diagonal

cbelow main diagonal
Table 3: CV-IOR-CyC-01 clinical validity ${ }^{\mathrm{a}}$

\begin{tabular}{|c|c|c|c|c|}
\hline Construct dimensions & Stages & Mean & SD & $\stackrel{p}{\mathbf{p}}$ \\
\hline \multirow{4}{*}{ Physical functioning } & I & 4.96 & 0.2 & \multirow{4}{*}{0.000} \\
\hline & II & 4.91 & 0.5 & \\
\hline & III & 4.82 & 0.5 & \\
\hline & IV & 4.57 & 0.7 & \\
\hline \multirow{4}{*}{$\begin{array}{l}\text { Psychosocial functioning } \\
\text { and family relationships }\end{array}$} & 1 & 4.47 & 0.5 & \multirow{4}{*}{0.000} \\
\hline & II & 4.36 & 0.6 & \\
\hline & III & 4.19 & 0.6 & \\
\hline & IV & 4.21 & 0.6 & \\
\hline \multirow{4}{*}{ Symptoms and side effects } & I & 4.72 & 0.4 & \multirow{4}{*}{0.005} \\
\hline & II & 4.53 & 0.6 & \\
\hline & III & 4.48 & 0.5 & \\
\hline & IV & 4.41 & 0.4 & \\
\hline \multirow{4}{*}{ HRQOL } & 1 & 4.44 & 0.3 & \multirow{4}{*}{0.000} \\
\hline & II & 4.34 & 0.5 & \\
\hline & III & 4.22 & 0.4 & \\
\hline & IV & 4.14 & 0.4 & \\
\hline
\end{tabular}

ameans and standard deviations of quality of life scores by clinical cancer stage and construct dimensions

bone-way ANOVA

Table 4: CV-IOR-CyC-01 predictive validity ${ }^{a}$

Domain/item (measurement times) ${ }^{\mathrm{a}}$

Physical functioning (before/at completion)

Physical functioning (at completion/one month after completion)

Psychosocial functioning and family relationships (before/at completion)

Psychosocial functioning and family relationships (at completion/ one month after completion)

1.53

Symptoms and side effects (before/at completion)

1.75

Symptoms and side effects (at completion/one month after completion)

HRQOL index (before/at completion)

HRQOL index (at completion/one month after

completion)

1.00

Perceived general heath (before/at completion)

Perceived general health (at completion/one month after completion)

Perceived HRQOL (before/at completion)

Perceived HRQOL (at completion/one month after completion)

HRQOL: health-related quality of life SRM: standardized response mean awith respect to cancer treatment (last radiotherapy or chemotherapy session) beffect size: $\mathrm{SRM}<0.2=$ small $\quad \mathrm{SRM} \geq 0.2$ but $<0.8=$ moderate $\mathrm{SRM} \geq 0.8=$ large

Response burden Mean completion time was 6.2 minutes (SD 3.1). Item nonresponse rates varied between $1.3 \%$ and $3.8 \%$. Unanswered items pertained to symptoms and side effects: going up stairs without help (1.3\%); deafness, tinnitus or blocked ear $(1.8 \%)$; acid reflux, bloating or sluggish digestion $(2.5 \%)$ and discomfort when ingesting cold and/or hot items (3.8).

\section{DISCUSSION}

This study's main contribution to public health—and specifically to oncology - is that it is the first to develop an instrument to measure HRQOL in patients with head and neck cancers that is adapted 
to Cuba's sociocultural conditions. The instrument encompasses negative emotional states; problems with social, family and partner relationships; and especially negative effects of radiotherapy, chemotherapy and surgery on body image, identified by patients. All these are aspects that other instruments used internationally (such as EORTC's QLQ H\&N-35 and FACTG's H\&N and nasopharyngeal modules) explore in much less detail.[21]

A multi-item, validated and improved instrument was constructed that, according to both experts and patients, addressed all facets needed to assess impact of nasopharyngeal, laryngeal, oral and mesopharyngeal cancer on HRQOL. It also provided clinimetric scales to measure cancer symptoms and treatment side effects.

Concerning internal consistency, CV-IOR-CyC-01 was homogeneous without being redundant. Test-retest reliability was acceptable, except for the symptoms and side effects domain. As expected, cancer patients receiving radiotherapy and chemotherapy continued to report side effects of cancer treatment well after completion. These items represent causal variables that express declining HRQOL, and therefore exhibit special characteristics during validation. Although test-retest correlations of items related to symptoms and side effects were low, these have an important negative impact on social functioning and on HRQOL, indicating they should be retained in the instrument.[22]

The multitrait multimethod matrix method corroborated convergent and discriminant validity and demonstrated that the domains included measure different aspects of the HRQOL construct. Although we used different methodologies, our evaluation of CVIOR-CyC-01 produced similar results to those of Oñate-Ocaña [23] and Arraras, [24] who validated different versions of EORTC's questionnaire.

Given that CV-IOR-CyC-01 was constructed mainly to evaluate HRQOL during patient monitoring, predictive validity is indispensable and even more important than clinical validity, because monitoring changes in HRQOL is essential for survival studies and for estimating cancer patients' prognosis.[25,26] In general, estimates of predictive validity were very satisfactory, even in the ungrouped items for perceived general health and perceived HRQOL. However, the physical functioning domain for head and neck cancer showed a moderate effect, since physical deterioration of aerodigestive tracts typically caused by cancer and surgical treatment had little effect on perceived HRQOL. Other authors have used prospective studies to evaluate capacity to measure clinically significant changes in patients in other anatomical areas.[27]

Nonresponse occurred in patients completing the self-administered questionnaire who decided to leave the answer blank when they did not have the symptom or side effect. This cause of nonresponse does not affect item validity and can be avoided by reviewing the questionnaire when the patient submits it.

The study has two limitations. One is related to external validity, since the questionnaire will be applicable only under similar conditions to those of Cuba, which depend on available cancer treatment. The second is a methodological limitation, concerning use of classical theory as the basis for validation. Classical theory is the most well-known and commonly used today, but under its assumptions, instrument psychometrics are not invariant, given that reliability coefficients depend on context and standards of living. Item response theory offers broader analytical possibilities but is more complex and difficult to interpret.[28]

\section{CONCLUSIONS}

CV-IOR-CyC-01 acceptably fulfills all metric criteria, mainly the basic traits for scales containing causal variables: predictive validity and interpretability. This supports its use in clinical trial protocols with nasopharyngeal, laryngeal, oral and mesopharyngeal cancer patients. - 1 h

\section{REFERENCES}

1. Urzúa A, Caqueo-Urízar A. Calidad de vida: una revisión del concepto. Ter Psicol [Internet]. 2012 Apr [cited 2016 May 21];30(1):61-71. Available from: http://www.redalyc.org/articulo .oa?id=78523000006. Spanish.

2. Arrarás $\mathrm{JI}$, Arias de la Vega F, Illarramendi JJ, Manterola A, Salgado E, Domínguez MA, et al. Calidad de vida relacionada con la salud en los servicios de Oncología del Hospital de Navarra. Grupo de Calidad de Vida de la EORTC. An Sist Sanit Navar. 2011 Jan-Apr;34(1):9-20. Spanish.

3. Waller A, Forshaw K, Bryant J, Mair S. Interventions for preparing patients for chemotherapy and radiotherapy: a systematic review. Support Care Cancer. 2014 Aug;22(8):2297-308.

4. National Health Statistics and Medical Records Division (CU). Anuario Estadístico de Salud 2010 [Internet]. Havana: Ministry of Public health (CU); 2011 Apr [cited 2016 Jun 27]. 199 p. Available from: http://files.sld.cu/dne/files/2011/04/anuario -2010-e-sin-graficos1.pdf. Spanish.

5. National Health Statistics and Medical Records Division (CU). Anuario Estadístico de Salud 2011 [Internet]. Havana: Ministry of Public Health (CU); 2012 May [cited 2016 Jun 27]. 233 p. Available from: http://files.sld.cu/bvscuba/files/2012/05/anua rio-2011-e.pdf. Spanish.

6. National Statistics and Medical Records Division (CU). Anuario Estadístico de Salud 2013
[Internet]. Havana: Ministry of Public Health (CU); 2014 [cited 2016 Jun 27]. 205 p. Available from: http://files.sld.cu/dne/files/2014/05/anuario -2013-esp-e.pdf. Spanish.

7. National Statistics and Medical Records Division (CU). Anuario Estadístico de Salud 2015 [Internet]. Havana: Ministry of Public Health (CU); 2016 Apr [cited 2016 Jun 27]. 206 p. Available from: http://files.sld.cu/dne/files/2016/04/Anuario 2015_electronico-1.pdf. Spanish.

8. Loimu $V$, Mäkitie AA, Bäck LJ, Sintonen $H$, Räsänen $P$, Roine R, et al. Health-related quality of life of head and neck cancer patients with successful oncological treatment. Eur Arch Otorhinolaryngol. 2015 Sep;272(9):2415-23.

9. Nguyen TV, Anota A, Brédart A, Monnier A Bosset JF, Mercier M. A longitudinal analysis of patient satisfaction with care and quality of life in ambulatory oncology based on the OUTPATSAT35 questionnaire. BMC Cancer. 2014 Jun 25;14:42.

10. Feldman DE, Lévesque J, Lemieux $\mathrm{V}$, Tourigny A, Lavoie J, Tousignant P. Primary Healthcare Organization and Quality-of-Life Outcomes for Persons with Chronic Disease. Health Policy. 2012 Feb;7(3):59-72.

11. Consiglio E, Belloso WH. Nuevos indicadores clínicos. La calidad de vida relacionada con la salud. Medicina (B Aires). 2003;63(2):172-8. Spanish.
12. Kazi R, Sayed S, Dwivedi RC. Clinical importance of quality of life measures in head and neck cancer. Indian J Cancer. 2010 Jul-Sep;47(3):237-8.

13. Bacallao J. Validity. In: Boslaugh S, editor. Encyclopedia of Epidemiology. New York: Sage; 2008. $1240 p$

14. Awad MA, Denic S, El Taji H. Validation of the European Organization for Research and Treatment of Cancer Quality of Life Questionnaires for Arabic-speaking Populations. Ann NY Acad Sci. 2008 Sep;1138:146-54.

15. Silveira AP, Gonçalves J, Sequeira T, Ribeiro C, Lopes C, Monteiro E, et al. Patient reported outcomes in head and neck cancer: selecting instruments for quality of life integration in clinical protocols. Head Neck Oncol [Internet]. 2010 Oct 31 [cited 2015 Jan 12];2:32. Availale from: https://www.ncbi.nlm.nih.gov/pmc/articles/ pmid/21040524/

16. Arias Valencia MM, Giraldo Mora CV. El rigor científico en la investigación cualitativa. Invest Educ Enferm. 2011 Oct-Dec;29(3):500-14. Spanish.

17. Morales VP, Uroza Sanz B, Blanco Blanco A. Construcción de escalas de actitudes tipo Likert: una guía práctica. 2nd ed. Madrid: Editorial Hespérides; 2003. 175 p. Spanish.

18. Fayer PM, Machin D. Quality of Life: The Assessment, Analysis and Reporting of Patient-Reported Outcomes. New York: John Wiley \& Sons; 2015 
Dec 5. Chapter 4, Scores and Measurements: Validity, Reliability, Sensitivity; p. 90-124.

19. Cohen J. Statistical Power Analysis for the Behavioral Sciences. New York: Academic Press; 1977. 474 p.

20. Fayer PM. Clinical Interpretation Quality of Life Assessment, Analysis and Interpretation. In: Fayer PM, Machin D, editors. Analysis and Interpretation. 2nd ed. New York: John Wiley \& Sons; 2013 May. 568 p.

21. Ojo B, Genden EM, Teng MS, Milbury K, Misiukiewicz KJ, Badr H. A systematic review of head and neck cancer quality of life assessment instruments. Oral Oncol. 2012 Oct;48(10):923-37.

22. Fayers PM, Hand DJ. Causal variables, indicator variables and measurement scales: an example from quality of life. J R Statist Soc A. 2002;165(Part 2):233-61.

23. Oñate-Ocaña LF, Alcántara-Pilar A, Vilar-Compte D, García-Hubard G, Rojas-Castillo E, AlvaradoAguilar S, et al. Validation of the Mexican Spanish Version of the EORTC C30 and STO22 questionnaires for the evaluation of health-related quality of life in patients with gastric cancer. Ann Surg Oncol. 2009 Jan;16(1):88-95

24. Arraras JI, Rico M, Vila M, Chicata V, Asin G, Martínez M, et al. The EORTC cancer outpatient satisfaction with care questionnaire in ambulatory radiotherapy: EORTC OUT-PATSAT35 RT. Validation study for Spanish patients. Psychooncology. 2010 Jun;19:657-64.
25. Browman GP, Berrang T, Smith S. Prognostic Tools for Cancer Survival: A Secondary Role for Quality-of-Life Measurement. J Clin Oncol. 2009 Jun 20;27(18):2902-4.

26. Montazeri A. Quality of life data as prognostic indicators of survival in cancer patients: an overview of the literature from 1982 to 2008 . Health Qual Life Outcomes. 2009 Dec 23;7:102.

27. Feise RJ, Michael Menke J. Functional rating index. A new valid and reliable instrument to measure the magnitude of clinical change in spinal conditions. Spine (Phila Pa 1976). 2001 Jan 1;26(1):78-87.

28. Muñiz J. Las teorías de los tests: teoría clásica y teoría de respuesta a los ítems Papeles Psicól. 2010;31(1):57-66. Spanish.

\section{THE AUTHORS}

Josefina Lugo-Alonso (Corresponding author: jlainor@infomed.sld.cu), physician specializing in biostatistics. Associate researcher, Clinical Research Department, National Oncology and Radiobiology Institute (INOR), Havana, Cuba.

José R. Díaz-Martínez, oncologist. Associate professor and researcher and chief, Head \& Neck Service, INOR, Havana, Cuba.
Nélido González-Fernández, oncologist. Associate professor and researcher, Head \& Neck Service, INOR, Havana, Cuba.

Mario Luzardo-Verde, mathematician with a doctorate in behavioral sciences. Professor, Psychology Faculty, University of the Republic of Uruguay, Montevideo, Uruguay.

Leticia Fernández-Garrote, dentist specializing in biostatistics with a doctorate in medical sciences. Full professor and researcher, National School of Public Health, Havana, Cuba.

Gladys E. López-Bujáns, dentist specializing in family dentistry. Instructor, Cira García Central Clinic, Havana, Cuba.

Argelia Collazo-de la Maza, oncologist. Associate researcher, Clinical Research Department INOR, Havana, Cuba.

Submitted: October 19, 2016

Approved for publication: June 30, 2017

Disclosures: None

\section{3rd International Congress on Community Genetics}

\section{Community Genetics in the Age of Genomics: Prevention is the Challenge}

November $14-17,2017$

Meliá Habana Hotel Convention Center

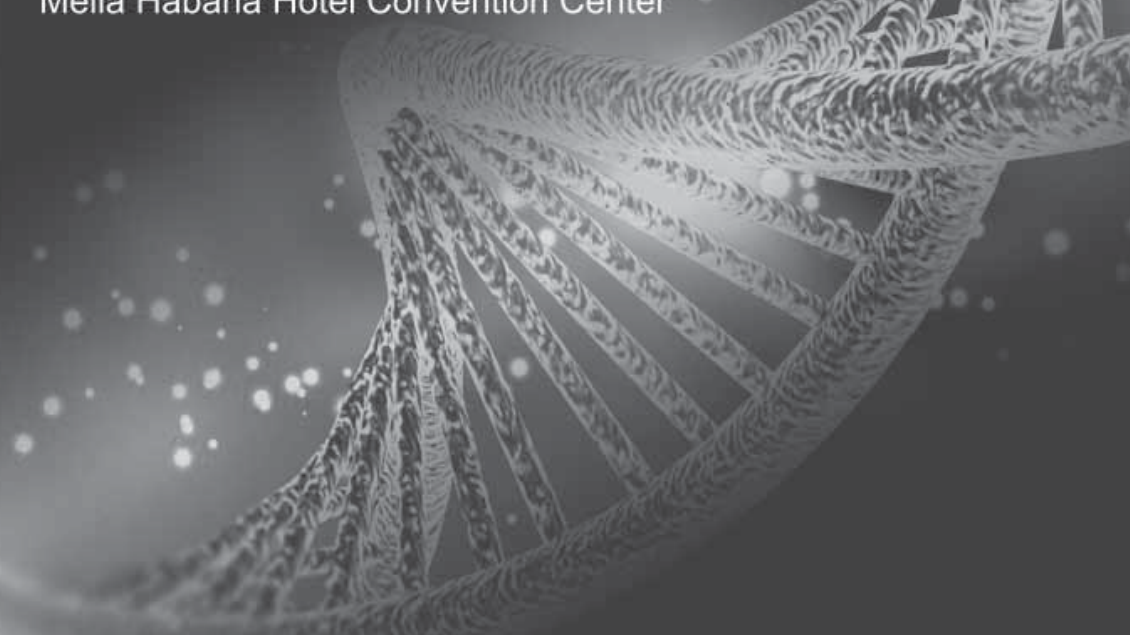

Sponsor: Cuban Society of Human Genetics

Languages: Spanish, English

Information: http://geneticacomunitaria2017.sld.cu

\section{Main themes:}

- Community genetics

- Clinical genetics

- Cytogenetics

- Molecular genetics

- Immunogenetics

- Genetics and cancer

- Ethics and genetics

- Genetics education

- Genetic diseases

- Pharmacogenetics

- Population genetics 